\title{
Hubungan Produk Tahu dan Tempe dalam Optimalisasi Laba (Keuntungan Maksimum) pada UD Wahyu di Kota Denpasar
}

\author{
AHMAD MAULA ABIDIN, I WAYAN WIDYANTARA, \\ I GUSTI AGUNG AYU AMBARAWATI
}

\author{
Program Studi Agribisnis, Fakultas Pertanian, Universitas Udayana \\ J1. PB. Sudirman Denpasar 80323 \\ Email: ahmadmaulaabidin@gmail.com \\ widyantaramkr@yahoo.com
}

\section{Abstract \\ Relationship of Products Tofu and Tempeh for the Optimization of Profits (Maximum Profits) at UD Wahyu in Denpasar City}

UD Wahyu is one of the largest industry tofu and tempeh in Denpasar, proved by its ability of the average monthly production reached 167.36 tons of tofu and 51.76 tons of tempeh. Problem faced by UD Wahyu is the selling price of tofu and tempeh remain the same every year and uncertain incurred costs causing change profits over time. The purposes of the research are to determine the production relationship between tofu and tempeh and to find out the optimal production of tofu and tempeh by UD Wahyu. Data collected by in-depth interview to the owner and observation to the local site of production. Data analysis techniques was using regression and maximum profit analysis by the marginal cost approach. The results showed that production relationship between tofu and tempeh is complementary. It means that any increase of tofu production will be followed by an increase in tempeh production. The optimal monthly production of tofu amounted to 69.582 tons and the optimal production of tempeh every month prevailed into two options, amounted to 32.3073 tons and 43.9101 tons respectively. Profits earned by UD Wahyu from production of 32.073 tons tempeh and 69.582 tons tofu between Rp 44.618 .449 and Rp 147.989.431. While profits earned by UD Wahyu production of tempeh 43.9101 tons and tofu 69.582 tons between $\mathrm{Rp} 112.318 .141$ and $\mathrm{Rp} 215.689 .123$. Average production of tofu and tempeh at UD Wahyu every month still exceeds the optimal production. To control costs, UD Wahyu is recommended to work on the optimal production.

Keywords: product relationships, production optimum, maximum profits

\section{Pendahuluan}

\subsection{Latar Belakang}

Menurut Soekartawi (2001), agroindustri adalah industri yang berbahan baku utama dari produk pertanian. Salah satu jenis agroindustri adalah industri tahu dan tempe karena memanfaatkan produk-produk pertanian. Industri tahu dan tempe yang berkembang di Kota Denpasar salah satunya yaitu UD Wahyu. Industri tahu dan 
tempe UD Wahyu berproduksi dengan teknologi sederhana dan tanpa bahan pengawet sejak tahun 1995. Setiap usaha termasuk UD Wahyu selalu mengkehendaki keuntungan. Keuntungan tersebut dapat dicapai dengan menyusun perencanaan laba yang baik. Ada tiga faktor yang dapat mempengaruhi laba perusahaan yaitu biaya, harga jual dan volume penjualan atau produksi (Halim dan Supomo, 2009).

Harga jual produk tahu dan tempe pada UD Wahyu selalu tetap setiap tahunnya yakni Rp 2.400.000 per ton untuk tahu dan harga tempe sebesar Rp 7.407.410 per ton. Banyaknya pesaing di Kota Denpasar membuat harga jual tahu dan tempe UD Wahyu tidak dapat ditingkatkan setiap tahunnya. Hal ini membuat peningkatan keuntungan hanya dapat dilakukan dengan penekanan biaya produksi. Akumulasi biaya yang dikeluarkan oleh UD Wahyu setiap periodenya mengalami perbedaan. Hal tersebut dikarenakan fluktuasi harga kedelai, jumlah bahan bakar, dan upah pekerja. Tidak menentunya biaya tersebut setiap tahun membuat UD Wahyu kesulitan dalam mencapai keuntungan yang diinginkan (keuntungan maksimum). Oleh karena itu, diperlukan analisis untuk mengetahui hubungan tahu dan tempe dalam memperoleh laba (keuntungan maksimum).

\subsection{Tujuan Penelitian}

Berdasarkan dengan rumusan masalah tersebut diatas, maka tujuan penelitian adalah sebagai berikut :

1. Mengetahui hubungan produk tahu dan tempe pada UD Wahyu.

2. Mengetahui jumlah produk tahu dan tempe yang harus di produksi oleh UD Wahyu untuk mendapatkan keuntungan maksimum (produksi optimal).

\section{Metodologi Penelitian}

\subsection{Lokasi dan Waktu Penelitian}

Penelitian ini dilakukan pada industri tahu dan tempe UD Wahyu di Jl. Tukad Buaji Gg. 27 No. 18, Denpasar. Pengambilan data dilakukan dari November 2016 sampai Januari 2017.

\subsection{Jenis dan Sumber Data}

Data yang digunakan dalam penelitian ini adalah data kualitatif dan data kuantitatif. Data kualitatif dalam penelitian ini meliputi gambaran umum tentang perusahaan dan standar operasional pembuatan (SOP) tahu dan tempe. Data kuantitatif berupa data runtun waktu (time series) yang meliputi data produksi, biaya total, harga, penerimaan, dan keuntungan.

Sumber data yang dipergunakan dalam penelitian ini adalah data primer dan data sekunder. Data primer meliputi harga jual tahu dan tempe serta gambaran umum tentang perusahaan yang diperoleh langsung dari Pak Fajar Wahyu Santoso selaku manajer perusahaan di lokasi penelitian. Data sekunder meliputi data produksi, biaya 
total, penerimaan, dan keuntungan yang diperoleh secara tidak langsung dari laporan bulanan UD Wahyu.

\subsection{Metode Pengumpulan Data}

Metode pengumpulan data yang digunakan yaitu wawancara mendalam dan observasi. Wawancara mendalam (indepth interview) merupakan proses memperoleh keterangan untuk tujuan penelitian dengan cara tanya jawab dan bertatap muka, dimana informan terlibat dalam kehidupan sosial yang relatif lama (Sutopo, 2006). Metode wawancara mendalam yang dilakukan adalah antara penulis dengan informan kunci, yakni Pak Fajar Wahyu Santoso selaku manajer perusahaan. Observasi adalah metode yang dilakukan dengan pengamatan langsung di lokasi penelitian untuk mengetahui kondisi dan fakta yang terjadi.

\subsection{Metode Analisis Data}

Analisis data dilakukan dengan menggunakan analisis komputer Microsoft Excel 2013 serta dikaji dengan menggunakan beberapa metode sebagai berikut.

\subsubsection{Uji kriteria statistika dengan uji $R^{2}$, uji $F$, dan uji $t$}

Menurut Tenaya (2009), uji kriteria statistika meliputi sebagai berikut :

1. Uji koefisien determinasi $\left(\mathrm{R}^{2}\right)$

Koefisien determinasi sama dengan $\mathrm{R}$ square yang dapat menunjukkan besarnya nilai variasi keragaman total variabel terikat yang dapat diterangkan oleh variabel bebas. Nilai koefisien determinasi terletak diantara nol sampai dengan nilai maksimum yaitu satu.

2. Uji F

Uji $\mathrm{F}$ digunakan untuk melihat apakah keseluruhan variabel bebas yang dimasukkan dalam persamaan secara bersamaan (simultan) berpengaruh terhadap variabel terikat yang ada. Nilai significance $F$ lebih besar dari $\alpha(0,05)$ menunjukkan variabel bebas tidak berpengaruh nyata. Nilai significance $F$ lebih kecil sama dengan $\alpha(0,05)$ menunjukkan variabel bebas berpengaruh nyata. Nilai significance $F$ lebih kecil sama dengan $\alpha(0,01)$ menunjukkan variabel bebas sangat berpengaruh nyata.

3. Uji $t$

Uji $t$ merupakan pengujian yang bertujuan untuk mengetahui variabel bebas secara parsial (individu) yang berpengaruh signifikan terhadap variabel terikat. Nilai $p$-value lebih besar dari $\alpha(0,05)$ menunjukkan variabel bebas tidak berpengaruh nyata. Nilai $p$-value lebih kecil sama dengan $\alpha(0,05)$ menunjukkan variabel bebas berpengaruh nyata. Nilai $p$-value lebih kecil sama dengan $\alpha(0,01)$ menunjukkan variabel bebas sangat berpengaruh nyata. 


\subsubsection{Analisis hubungan produk tahu terhadap tempe}

Menurut Suratiyah (2006), product-product relationship adalah hubungan antara produksi yang satu dengan produksi yang lainnya. Hubungan tahu dan tempe dapat diketahui dengan fungsi persamaan sebagai berikut :

$$
\mathrm{Q}_{\text {tempe }}=\mathrm{a}+\mathrm{b} \mathrm{Q}_{\text {tahu }}
$$

Persamaan yang terbentuk terlebih dahulu harus memenuhi uji kriteria statistika. Hubungan produk tahu dan produk tempe ditentukan dari koefisien persamaan yang terbentuk. Nilai koefisien b lebih besar dari 0 maka hubungan produk tahu dan tempe bersifat komplementer. Nilai koefisien b sama dengan 0 maka hubungan produk tahu dan tempe bersifat suplementer. Nilai koefisien b lebih kecil dari maka hubungan produk tahu dan tempe bersifat kompetitif.

\subsubsection{Pendugaan fungsi biaya}

Pendugaan fungsi biaya dilakukan melalui analisis regresi antara biaya total sebagai variabel terikat (dependent) dengan besarnya produksi sebagai variabel bebas (independent) menggunakan data time series. Analisis regresi pendugaan fungsi biaya yang digunakan adalah bentuk kubik dan bentuk kuadrat.

1. Analisis regresi bentuk kubik

Menururut Gaspersz (2000), model fungsi biaya total (TC) regresi bentuk kubik dapat dinyatakan, sebagai berikut :

$$
\mathrm{TC}=\mathrm{a}+\mathrm{bQ}+\mathrm{cQ} \mathrm{Q}^{2}+\mathrm{dQ}^{3}
$$

2. Analisis regresi bentuk kuadrat

Model fungsi biaya total (TC) regresi bentuk kuadrat dapat dinyatakan, sebagai berikut :

$$
\mathrm{TC}=\mathrm{a}+\mathrm{bQ}+\mathrm{cQ}^{2}
$$

Keterangan :

TC = Biaya total dari tahu atau tempe.

$\mathrm{Q}=$ Produksi dari tahu dan tempe.

$\mathrm{a}, \mathrm{b}, \mathrm{c}, \mathrm{d}=$ Koefisien dari fungsi biaya total tahu atau tempe.

$\mathrm{Q}^{2}, \mathrm{Q}^{3}=$ Bentuk kuadrat dan kubik dari $\mathrm{Q}$ tahu atau tempe.

Persamaan yang terbentuk terlebih dahulu harus memenuhi uji kriteria statistika. Menurut Hanani dan Asmara (2011), persamaan regresi yang menghasilkan koefisien determinasi $\left(\mathrm{R}^{2}\right)$ yang tertinggi dimana persamaan tersebut mampu menjelaskan proporsi tertinggi dari variabilitas pada variabel dependen (TC). Oleh sebab itu, dalam menentukan bentuk persamaan dilihat dari nilai $\left(\mathrm{R}^{2}\right)$ terbesar. 


\subsubsection{Analisis keuntungan maksimum dengan pendekatan marjinal}

Menururut Rahardja dan Manurung (1999), laba maksimum tercapai bila turunan pertama fungsi $\pi(\partial \pi / \partial \mathrm{Q})$ sama dengan nol dan nilainya sama dengan nilai turunan pertama TR ( $\partial \mathrm{TR} / \partial \mathrm{Q}$ atau MR) dikurangi nilai turunan pertama TC ( $\partial \mathrm{TC} /$ $\partial \mathrm{Q}$ atau $\mathrm{MC})$.

$$
\mathrm{MR}=\mathrm{MC}
$$

Keterangan :

$\pi \quad=$ Keuntungan.

MR = Penerimaan marjinal (turunan dari total penerimaan).

MC = Biaya marjinal (turunan pertama dari biaya total).

Harga jual tahu dan tempe UD Wahyu tetap setiap tahunnya. Menurut Widyantara (2013), harga output (Pq) sering tidak mengalami perubahan atau tetap (given) sehingga MR = Pq. Menurut Burhan (2006), harga output yang konstan menyebabkan MR sama dengan harga output sehingga hasil dapat ditulis $\mathrm{Pq}=\mathrm{MC}$. Oleh karena itu, keuntungan maksimum tahu dan tempe terjadi pada saat $\mathrm{Pq}=\mathrm{MC}$.

\subsubsection{Analisis fungsi keuntungan}

Keuntungan merupakan selisih total penerimaan dengan biaya total. Total penerimaan akan berkaitan dengan jumlah produksi tahu dan tempe serta harga jual. Biaya total yang dikeluarkan juga berkaitan dengan jumlah produksi tahu dan tempe. Oleh sebab itu, keuntungan akan berkaitan juga dengan produksi tahu dan tempe, sehingga membentuk fungsi sebagai berikut :

$$
\pi=\mathrm{a}+\mathrm{bQ}_{\text {tahu }}+\mathrm{cQ}_{\text {tempe }}
$$

Persamaan yang terbentuk terlebih dahulu harus memenuhi uji kriteria statistika. Persamaan yang dapat digunakan untuk mengestimasikan keuntungan adalah persamaan yang memenuhi uji kriteria statistika.

\section{Hasil dan Pembahasan}

\subsection{Hubungan Produk Tahu dan Tempe pada UD Wahyu}

Hasil analisis hubungan produk tahu dan tempe mendapatkan persamaan sebagai berikut :

$$
\mathrm{Q}_{\text {tempe }}=13,4526+0,2289 \mathrm{Q}_{\mathrm{tahu}}
$$

Berdasarkan persamaan tersebut, significance $F$ dan p-value $\mathrm{Q}_{\text {tahu }}$ bernilai sama

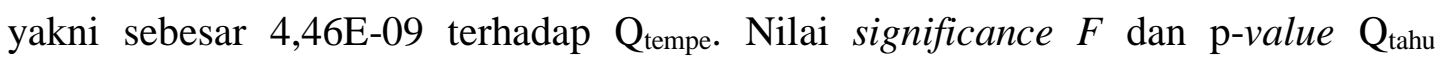


tersebut menunjukkan bahwa $\mathrm{Q}_{\text {tahu }}$ berpengaruh sangat nyata terhadap $\mathrm{Q}_{\text {tempe }}$ karena dibawah taraf nyata $(\alpha=0,01)$. Hal tersebut membuat persamaan tersebut dapat digunakan untuk analisis. Koefisien determinasi $\left(\mathrm{R}^{2}\right)$ sebesar 0,652 menunjukkan variasi keragaman $\mathrm{Q}_{\text {tempe }}$ dapat diterangkan atau dijelaskan oleh $\mathrm{Q}_{\text {tahu }}$ sebesar 65,2\% dan sisanya dapat dijelaskan variabel lainnya. Grafik hubungan produk tahu dan tempe disajikan pada Gambar 1.

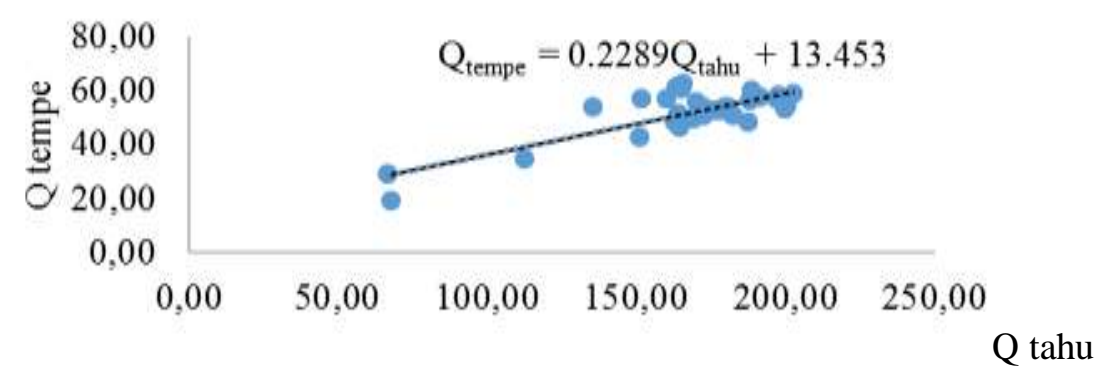

Gambar 1.

Hubungan Produk Tahu dan Tempe

Gambar 1 menunjukkan setiap kenaikan produksi tahu akan diikuti dengan kenaikan produksi tempe. Setiap penurunan produksi tahu akan diikuti dengan penurunan produksi tempe. Hal ini menyebabkan daya desak produksi tahu terhadap tempe akan selalu berkaitan dan bernilai positif. Hal tersebut membuat hubungan produksi tahu dan tempe bersifat komplementer. Hubungan yang bersifat komplementer menunjukkan tahu dan tempe memberikan manfaat atau kepuasan bagi konsumen jika dikonsumsi bersama-sama. Dengan kata lain, tahu dan tempe sebagai produk yang saling melengkapi. Hal ini disebabkan selera konsumen terhadap tempe mencapai kepuasan saat diikuti dengan konsumsi tahu juga. Konsumen memilih kedua produk secara bersamaan juga disebabkan harga tempe dan tahu dari UD Wahyu yang terjangkau.

\subsection{Produksi Optimal Tahu dan Tempe untuk Mendapatkan Keuntungan Maksimal}

\subsubsection{Pendugaan fungsi biaya total tahu}

Pendugaan fungsi biaya total tahu menggunakan model persamaan bentuk kuadrat. Hal tersebut disebabkan nilai variabel $\mathrm{Q}_{\text {tahu}}, \mathrm{Q}^{2}$ tahu, dan $\mathrm{Q}^{3}$ tahu bentuk kubik secara parsial tidak signifikan. Hasil pendugaan fungsi biaya total tahu bentuk kuadrat, mendapatkan persamaan sebagai berikut :

$$
\mathrm{TC}_{\text {tahu }}=-60.955 .833,17+2.955 .495,027 \mathrm{Q}_{\mathrm{tahu}}-3.991,6601 \mathrm{Q}^{2} \text { tahu }
$$

Berdasarkan persamaan tersebut, significance $\mathrm{F}$, p-value $\mathrm{Q}_{\mathrm{tahu}}$, dan $\mathrm{p}$-value $\mathrm{Q}^{2}$ tahu masing-masing sebesar 3,39E-17, 0,0000847, dan 0,00101. Nilai significance F tersebut menunjukkan bahwa $\mathrm{Q}_{\text {tahu }}$ dan $\mathrm{Q}^{2}$ tahu secara bersama-sama berpengaruh 
sangat nyata terhadap $\mathrm{TC}_{\text {tahu }}$ karena dibawah taraf nyata $(\alpha=0,01)$. Nilai $\mathrm{p}$-value $\mathrm{Q}_{\text {tahu }}$ dan $\mathrm{p}$-value $\mathrm{Q}^{2}$ tahu menunjukkan bahwa $\mathrm{Q}_{\text {tahu }}$ dan $\mathrm{Q}^{2}$ tahu secara individu juga berpengaruh sangat nyata terhadap $\mathrm{TC}_{\text {tahu }}$ karena dibawah taraf nyata $(\alpha=0,01)$. Koefisien determinasi $\left(\mathrm{R}^{2}\right)$ persamaan tersebut sebesar 0,9065 , menunjukkan variasi keragaman $\mathrm{TC}_{\text {tahu }}$ dapat dijelaskan oleh keragaman $\mathrm{Q}_{\text {tahu }}$ dan $\mathrm{Q}^{2}$ tahu sebesar 90,65\% dan sisanya dapat dijelaskan oleh variabel lainnya. Nilai double standard error pada persamaan tersebut sebesar 38.435.278,28 memberikan arti bahwa biaya total tahu secara aktual berada pada interval $\pm \mathrm{Rp}$ 38.435.278,28. Oleh sebab itu, analisis fungsi biaya total tahu bentuk kuadrat dapat diterima secara statistik sehingga dapat digunakan untuk perhitungan selanjutnya.

\subsubsection{Pendugaan fungsi biaya total tempe}

Pendugaan fungsi biaya total tempe lebih memilih menggunakan model persamaan bentuk kubik karena nilai koefisien determinasi $\left(\mathrm{R}^{2}\right)$ bentuk kubik lebih besar. Hasil pendugaan fungsi biaya total tempe bentuk kubik, mendapatkan persamaan sebagai berikut :

$$
\begin{aligned}
& \mathrm{TC}_{\text {tempe }}=450.403 .167,004-33.336 .196,44 \mathrm{Q}_{\text {tempe }}+1.094 .508,87 \mathrm{Q}^{2} \text { tempe } \\
& -9.573,57 \mathrm{Q}^{3} \text { tem }
\end{aligned}
$$

Berdasarkan persamaan tersebut, significance $\mathrm{F}$, $\mathrm{p}$-value $\mathrm{Q}_{\text {tempe, }} \mathrm{p}$-value $\mathrm{Q}^{2}$ tempe, dan $\mathrm{p}$-value $\mathrm{Q}^{3}$ tempe masing-masing sebesar 1,32E-12, 0,0159, 0,001, dan 0,0005. Nilai significance $\mathrm{F}$ tersebut menunjukkan bahwa $\mathrm{Q}_{\text {tempe, }} \mathrm{Q}^{2}$ tempe, dan $\mathrm{Q}^{3}$ tempe secara bersama-sama berpengaruh sangat nyata terhadap $\mathrm{TC}_{\text {tempe }}$ karena dibawah taraf nyata $(\alpha=0,01)$. Nilai $\mathrm{p}$-value $\mathrm{Q}_{\text {tempe, }} \mathrm{p}$-value $\mathrm{Q}^{2}$ tempe, dan $\mathrm{Q}^{3}$ tempe tersebut menunjukkan bahwa $\mathrm{Q}_{\text {tempe, }} \mathrm{Q}^{2}$ tempe, dan $\mathrm{Q}^{3}$ tempe secara individu juga berpengaruh sangat nyata terhadap $\mathrm{TC}_{\text {tahu }}$ karena dibawah taraf nyata $(\alpha=0,01)$. Koefisien determinasi $\left(\mathrm{R}^{2}\right)$ persamaan tersebut sebesar 0,8439 , menunjukkan variasi keragaman $\mathrm{TC}_{\text {tempe }}$ dapat dijelaskan oleh keragaman $\mathrm{Q}_{\text {tempe, }} \mathrm{Q}^{2}$ tempe, dan $\mathrm{Q}^{3}$ tempe sebesar $84,39 \%$ dan sisanya dapat dijelaskan oleh variabel lainnya. Nilai double standard error pada persamaan tersebut sebesar 40.007.857,76, memberikan arti bahwa biaya total tempe secara aktual berada pada interval \pm Rp 40.007857,76. Oleh sebab itu, analisis fungsi biaya total tempe bentuk kubik dapat diterima secara statistik sehingga dapat digunakan untuk perhitungan selanjutnya.

\subsubsection{Produksi tahu optimal}

Hasil perhitungan produksi tahu optimal mendapatkan hasil produksi tahu ( $\left.Q_{\text {tahu }}\right)$ sebesar 69,582 ton. Hasil perhitungan tersebut menunjukkan bahwa keuntungan maksimum dengan pendekatan marjinal akan tercapai pada saat produksi tahu sebesar 69,582 ton per bulan. Produksi tahu optimal sebesar 69,582 ton menghabiskan kedelai sebesar 14,056 ton. Hal ini berbeda dengan produksi tahu rata- 
rata UD Wahyu setiap bulannya yakni sebesar 167,36 ton setidaknya menghabiskan kedelai sebesar 33,806 ton setiap bulannya.

\subsubsection{Produksi tempe optimal}

Hasil perhitungan produksi tempe optimal mendapatkan hasil produksi tempe (Qtempe) sebesar 32,3073 ton dan 43,9101 ton. Hasil perhitungan tersebut menunjukkan bahwa keuntungan maksimum dengan pendekatan marjinal akan tercapai pada saat produksi tempe sebesar 32,3073 ton dan 43, 9101 ton per bulan. Produksi tempe optimal sebesar 32,3073 ton dan 43,9101 ton menghabiskan kedelai masing-masing sebesar 20,709 ton dan 28,146 ton. Hal ini berbeda dengan produksi tempe rata-rata UD Wahyu setiap bulannya yakni sebesar 51,76 ton setidaknya menghabiskan kedelai sebesar 33,178 ton setiap bulannya.

\subsection{Keuntungan pada Produksi Optimal}

Hasil persamaan fungsi keuntungan yang diperoleh yakni sebagai berikut :

$$
\pi=-52.653 .935,37-568.363,2795 \mathrm{Q}_{\text {tahu }}+5.834 .771,996 \mathrm{Q}_{\text {tempe }} .
$$

Berdasarkan persamaan tersebut, Nilai significance $\mathrm{F}, \mathrm{p}$-value $\mathrm{Q}_{\mathrm{tahu}}$, dan $\mathrm{p}$ value $\mathrm{Q}_{\text {tempe }}$ masing-masing sebesar 3,77E-09, 0,025, dan 1,01E-07. Nilai significance $\mathrm{F}$ tersebut menunjukkan bahwa $\mathrm{Q}_{\text {tahu }}$ dan $\mathrm{Q}_{\text {tempe }}$ secara bersama-sama berpengaruh sangat nyata terhadap $\pi$ karena dibawah taraf nyata $(\alpha=0,01)$. Nilai $p$ value $\mathrm{Q}_{\text {tahu }}$ dan $\mathrm{p}$-value $\mathrm{Q}_{\text {tempe }}$ tersebut menunjukkan bahwa $\mathrm{Q}_{\text {tahu }}$ secara individu berpengaruh nyata terhadap $\pi$ karena dibawah taraf nyata $(\alpha=0,05)$, sedangkan $Q_{\text {tempe }}$ secara individu berpengaruh sangat nyata terhadap $\pi$ karena dibawah taraf nyata $(\alpha=0,01)$. Koefisien determinasi $\left(\mathrm{R}^{2}\right)$ persamaan tersebut sebesar 0,7025 , menunjukkan variasi keragaman $\pi$ dapat dijelaskan oleh keragaman $\mathrm{Q}_{\text {tahu }}$ dan $\mathrm{Q}_{\text {tempe }}$ sebesar 70,25\% dan sisanya dapat dijelaskan oleh variabel lainnya. Nilai double standard error pada persamaan tersebut sebesar 25.842.745,45 memberikan arti bahwa keuntungan secara aktual berada pada interval \pm Rp 25.842.745,45. Oleh sebab itu, analisis fungsi keuntungan dapat diterima secara statistik sehingga dapat digunakan untuk perhitungan selanjutnya.

Berdasarkan persamaan fungsi keuntungan yang telah didapatkan, keuntungan UD Wahyu pada produksi optimal yakni sebagai berikut :

1. Keuntungan UD Wahyu pada produksi tahu 69,582 ton dan tempe 32,073 ton berkisar antara Rp 44.618.449 sampai dengan Rp 147.989.431.

2. Keuntungan UD Wahyu pada produksi tahu 69,582 ton dan tempe 43,9101 ton berkisar antara Rp 112.318.141 sampai dengan Rp 215.689.123.

Berdasarkan hasil analisis terlihat bahwa produksi tahu dan tempe UD Wahyu berada di atas produksi optimal. Hal ini disebabkan UD Wahyu selalu berusaha meningkatkan keuntungan dengan melakukan penjualan sebanyak-banyaknya (maximum selling). Maximum selling tersebut dilakukan karena keuntungan tidak 
dapat ditingkatkan dengan meningkatkan harga jual tahu dan tempe. Menurut Pak Wahyu apabila UD Wahyu meningkatkan harga jual tahu dan tempe penjualan akan berkurang. Hal ini disebabkan sales (pedagang eceran) yang ada pada UD Wahyu lebih memilih untuk mengambil produk dari Industri tahu dan tempe dengan harga yang lebih murah. Oleh karena itu UD Wahyu lebih memilih untuk meningkatkan penerimaan melalui peningkatan penjualan.

Keuntungan per unit yang didapatkan UD Wahyu pada saat produksi tahu optimal (69,582 ton) yaitu sebesar Rp 598.281,43, sedangkan saat produksi tahu lebih besar yaitu 197,475 ton keuntungan per unit yang didapatkan sebesar Rp $730.471,20$. Keuntungan per unit yang didapatkan UD Wahyu pada saat produksi tempe optimal (32,073 ton dan 43,9101 ton) masing-masing sebesar Rp 1.434.345,39 dan $\operatorname{Rp} 885.049,64$. Kondisi akan berbeda pada saat produksi tempe lebih besar yaitu 62,426 ton maka keuntungan per unit yang didapatkan sebesar Rp 2.572.286,95. Keuntungan yang didapatkan akan lebih besar apabila produksi tahu dan tempe yang dilakukan semakin besar. Oleh karena itu, UD Wahyu menggunakan maximum selling agar keuntungan yang didapatkan semakin besar.

Imbas yang ditimbulkan dari maximum selling yaitu UD Wahyu mengabaikan resiko yang akan muncul akibat produksi dalam jumlah besar. Meskipun demikian, UD Wahyu tetap memperoleh keuntungan atas sejumlah produksi tahu dan tempe yang dilakukan selama ini. Keuntungan tetap terjadi karena kenaikan biaya total yang dikeluarkan mampu diikuti dengan peningkatan penerimaan dari hasil jual tahu dan tempe tersebut. Kondisi akan berbeda ketika peningkatan produksi hanya meningkatkan biaya produksi tanpa diikuti peningkatan penerimaan yang besar pula. UD Wahyu pada kondisi tersebut mengalami kerugian. Melihat kapasitas produksi yang mampu dilakukan UD Wahyu merupakan cara untuk menghindari kerugian. Persamaan fungsi keuntungan yang sudah didapatkan juga dapat digunakan untuk mengetahui keuntungan UD Wahyu. Misalkan ketika UD Wahyu ingin melakukan produksi tahu $\left(\mathrm{Q}_{\text {tahu }}\right)$ sebesar 108,650 ton dan produksi tempe $\left(\mathrm{Q}_{\text {tempe }}\right)$ 47,395 ton maka UD Wahyu mendapatkan keuntungan berkisar sebesar Rp 136.289.667,06 sampai dengan Rp 187.975.159,06. Meskipun produksi di atas mendapatkan keuntungan lebih besar tetapi dengan melakukan produksi pada kondisi optimal juga sudah memperoleh keuntungan. UD Wahyu dapat menghindari biaya yang timbul akibat produksi yang berlebihan seperti kerusakan peralatan dan upah lembur karyawan. Oleh karena itu UD Wahyu lebih baik melakukan produksi tahu dan tempe pada keadaan optimal $\left(\mathrm{Q}_{\text {tahu }}=69,582\right.$ ton dan $\mathrm{Q}_{\text {tempe }}=32,073$ ton atau 43,9101 ton). 


\section{Simpulan dan Saran}

\subsection{Simpulan}

Berdasarkan hasil penilitian dan pembahasan, dapat disimpulkan sebagai berikut :

1. Hubungan produksi tahu dan tempe pada UD Wahyu bersifat komplementer. Hubungan komplementer membuat setiap kenaikan produksi tahu akan diikuti dengan kenaikan produksi tempe dan setiap penurunan produksi tempe akan diikuti dengan penurunan produksi tahu.

2. Produksi tahu dan tempe optimal pada UD Wahyu sebagai berikut :

a. Produksi optimal yang seharusnya dilakukan UD Wahyu setiap bulan sebesar 69,582 ton, sedangkan produksi tahu rata-rata UD Wahyu setiap bulan sebesar 167,36 ton melebihi produksi optimal.

b. Produksi tempe optimal yang seharusnya dilakukan UD Wahyu setiap bulan sebesar 32,3073 ton dan 43, 9101, sedangkan produksi tempe ratarata UD Wahyu setiap bulan sebesar 51,76 ton melebihi produksi optimal.

3. Kentungan yang didapatkan UD Wahyu pada produksi optimal sebagai berikut:

a. Keuntungan UD Wahyu pada produksi tahu 69,582 ton dan tempe 32,073 ton berkisar antara Rp 44.618.449 sampai dengan Rp 147.989.431.

b. Keuntungan UD Wahyu pada produksi tahu 69,582 ton dan tempe 43,9101 ton berkisaran antara Rp 112.318.141 sampai dengan Rp 215.689.123.

\subsection{Saran}

Berdasarkan hasil penelitian yang telah dilakukan maka dapat diberikan beberapa saran untuk kebaikan UD Wahyu, sebagai berikut :

1. Persamaan fungsi biaya total yang dihasilkan dapat digunakan UD Wahyu untuk memperkirakan biaya yang akan dikeluarkan. Keuntungan masing-masing dari tahu dan tempe juga dapat diperkirakan dengan mengurangi jumlah estimasi biaya terhadap penerimaan hasil penjualan.

2. UD Wahyu sebaiknya berproduksi pada tingkat produksi optimal untuk menghindari resiko dan biaya-biaya berlebihan seperti kerusakan alat dan biaya bahan baku.

3. UD Wahyu tidak perlu melakukan diferensiasi produk atau pembedaan salah satu produk tahu dan tempe agar lebih diminati konsumen karena setiap kenaikan dan penurunan jumlah permintaan konsumen terhadap tahu dan tempe pada UD Wahyu akan saling berkaitan dan searah.

\section{Ucapan Terimakasih}

Ucapan terimakasih ini peneliti tujukan kepada seluruh pihak yang telah membantu dalam pelaksanaan penelitian hingga karya ilmiah ini bisa dipublikasikan dalam e-jurnal. 


\section{Daftar Pustaka}

Burhan, U. 2006. Konsep Dasar Teori Ekonomi Mikro. Malang : BPFE UNIBRA.

Gasperz, V. 2000. Ekonomi Manajerial Pembuatan Keputusan Bisnis. Jakarta : Gramedia Pustaka Utama.

Halim, A. dan Supomo, B. 2009. Akuntansi Manajemen. Yogyakarta: BPFE.

Hanani dan Asmara. 2011. Estimasi Fungsi Biaya pada Usaha Pembuatan Chip Ubi Kayu Sebagai Bahan Baku Mocaf. Agrise, 11:1412-1425.

Rahardja, P. dan Manurung, M. (1999). Teori Ekonomi Mikro : Suatu Pengantar, Edisi Revisi. Jakarta : LPFE UI.

Soekartawi. 2001. Pengantar Agroindustri, Ed.1, Cet. 2. Jakarta : Raja Grafindo.

Suratiyah. 2006. Ilmu Usahatani. Jakarta : Penebar Swadaya.

Sutopo, H.B. 2006. Metode Penelitian Kualitatif. Surakarta: UNS Press.

Tenaya, I M. N. 2009. Bahan Kuliah Ekonometrika Program Studi Agribisnis. Laboratorium Statistika. Fakultas Pertanian Universitas Udayana.

Widyantara. 2013. Pengantar Ekonomi Pertanian. Bahan Ajar. Denpasar : Program Studi Agribisnis Fakultas Pertanian Universitas Udayana. 